\title{
Study of the Relationship between Chinese College Students' International Posture and Their Intercultural Willingness to Communicate
}

\author{
Güliz Ulu, Fan Weiwei, Shi Yu* \\ Huazhong University of Science and Technology, Wuhan, China \\ Email: gulizulu@hust.edu.cn, fanweiwei@hust.edu.cn, ${ }^{*}$ shiyu@hust.edu.cn
}

Received 1 June 2015; accepted 30 July 2015; published 4 August 2015

Copyright (C) 2015 by authors and Scientific Research Publishing Inc. This work is licensed under the Creative Commons Attribution International License (CC BY). http://creativecommons.org/licenses/by/4.0/

\section{(c) (i) Open Access}

\begin{abstract}
This paper involves an investigation of the relationship between Chinese college students' international posture and their intercultural willingness to communicate (IWTC) by means of questionnaires obtained from 167 Chinese college students. The results of the Pearson correlation show that there is a significant positive relationship between international posture and IWTC. In addition, the results of the multiple linear regressions indicate that Intercultural Friendship Orientation in English learning that is one factor of the international posture can significantly predict students' IWTC.
\end{abstract}

\section{Keywords}

International Willingness to Communicate, International Posture

\section{Introduction}

The rapid development of globalization has triggered an intense focus on intercultural communication. As one of the most important predispositions of intercultural communication behavior, the IWTC (International Willingness to Communicate) has undoubtedly attracted the attention of the researchers. IWTC is defined as one's predisposition to initiate intercultural communication encounters (Kassing, 1997). To improve students' intercultural willingness to communicate should lead to positive attitude towards intercultural communication behavior and finally initiate the actual successful intercultural communication. In order to understand how to im-

"Corresponding author.

How to cite this paper: Ulu, G., Fan Weiwei, \& Shi Yu (2015). Study of the Relationship between Chinese College Students' International Posture and Their Intercultural Willingness to Communicate. Chinese Studies, 4, 77-82.

http://dx.doi.org/10.4236/chnstd.2015.43012 
prove students' IWTC, the factors that have strong impact on IWTC should be identified in the most preliminary stage. Such influencing factors include intercultural communication apprehension (an individual level of fear associated with either real or anticipated situation with another person or persons) (McCroskey \& Baer, 1985), intercultural communication anxiety, ethnocentrism, frequency of international interactions, international posture and overseas friendship (Lin \& Rancer, 2003; Pan, 2007; Roach \& Olaniram, 2001; Gareis, Merkin, \& Goldman, 2011; Yashima, 2002).

Among all the above-mentioned factors, the international posture has been regarded as an important factor which can strongly affect Asian students' IWTC (Yashima, 2002). However, Yashima's study focused only on Japanese college students. Few empirical studies have investigated the influence of international posture on Chinese college students' IWTC. Therefore, this study aims to investigate the relationship between Chinese college students' international posture and their IWTC.

\section{Literature Review}

We would like to get a brief review of the main studies in the following aspects such as the intercultural willingness to communicate and international posture.

\subsection{Intercultural Willingness to Communicate}

The concept of IWTC was first proposed by Kassing (1997) who defined it as one's predisposition to initiate intercultural communication encounters. The concept is related, but distinct from the construct of WTC (McCroskey \& Richmond, 1991). WTC concerns people's willingness to communicate with friends, acquaintances, and strangers who are speaking the same language in a variety of settings (e.g.: dyad, group, meeting, public), whereas IWTC concerns people's willingness to engage in communication encounters with people of different races and cultures who are speaking other languages.

\subsection{International Posture}

The concept of international posture firstly advanced by Yashima (2002) is based on the foreign language learning environment where the English language learners have little contact with native speakers. It is natural that those English learners will not hold a clear specific reaction towards the English-speaking community. To those foreign language learners, English seems to represent something related to the foreign countries and foreigners. However, some students hold a positive attitude toward what English symbolizes while others do not. Such affective attitude can be defined as the international posture (Yashima, 2002).

Yashima et al. have conducted a series of studies with Japanese students to demonstrate the relationship between international posture and second language willingness to communicate (Yashima, 2002; Yashima et al., 2004; Yashima \& Zenuk-Nishide, 2008). All the studies proved that there was a significant positive relationship between international posture and Japanese students' willingness to communicate in English. The importance of international posture has not only been proved in the Japanese English learning environment, but also in China. Errington (2009) used the L2 learning motivation and Yashima's concept of international posture to investigate the effect of EFL teaching in China. The findings show that international posture affects Chinese students' L2 learning motivation positively. The higher a student's international posture is, the stronger motivation he has.

However, the relationship between Chinese students' international posture and their IWTC has seldom been investigated. Hence, our study will explore such relationship through the questionnaire. Our research questions are:

RQ1: What is the relationship between Chinese college students' international posture and their IWTC?

RQ2: How does the students' international posture predict their IWTC?

\section{Method}

\subsection{Participants}

Data were collected from students in a university located in the central part of China. A total of 167 subjects (99 males, 68 females) completed the instruments anonymously and on a volunteer basis. The average age was 20.12 years old. 


\subsection{Measurements}

Intercultural Willingness to Communicate (IWTC) Scale Students' Intercultural willingness to communicate (IWTC) was measured by a 12-item instrument developed by Kassing (1997). Six items were written to reflect intercultural willingness to communicate (e.g., Talk with someone from another culture). These items were interspersed between the six filler items used on the WTC scale (McCroskey, 1992) (e.g., Talk with a close friend). The subjects are requested to write down the percentage of times they would choose to communicate in each type of situation. The percentage is from 0 (which means never) to 100 (which means always). The Cronbach's $\alpha$ with the current population is 0.813 , which means that the IWTC scale holds high reliability. In order to help students to get a full understanding of the content, all the items were translated into Chinese.

International Posture Scale To measure the level of international posture, the participants were asked to complete Yashima's (2002) revised 19-item international posture scale. This scale consists of four factors: intercultural friendship orientation (e.g., I'd like to make friends with foreigners); approach-avoidance tendency (e.g., I would like to talk to an international student if there is one at school); interest in international vacation/activities (e.g., I want to work in an international organization such as the United Nations); and interest in foreign affairs (e.g., I often read and watch news about foreign countries). Ratings were recorded on Likert 5 -point scale with " 1 " meaning "strongly disagree" and " 5 " meaning "strongly agree”. The lowest score for international posture is 19 while the highest one is 95. The scores for each factor are the mean scores of all the items of that factor. The Cronbach's $\alpha$ with the current population is 0.803 which means that the international posture scale holds high reliability.

\section{Results}

In order to examine the relationship between international posture and IWTC, Pearson product-moment correlation was conducted. The Pearson product-moment correlation coefficient is a measure of the strength and direction of association that exists between two variables. SPSS 17.0 was used to check whether our data can adopt the Pearson product-moment first. It was found that all the variables were measured in the interval level; there were linear relationships between every two variables; there were no significant outliers; all the variables were approximately normally distributed. Since all the four assumptions of using Pearson product-moment correlation were fulfilled, the Pearson product-moment correlation was adopted. The results of the students' scores in international posture and its four factors and their correlation with the IWTC are shown in Table 1.

Table 1 illustrates that students' whole scores for international posture have reached 61.35 compared with the highest score of 95. Such scores indicate that Chinese students hold a relatively medium to high degree of international posture. In the Likert 5-point scale, the high frequency use indicates that the mean score should be equal to or above 3.5, the medium frequency use shows that the mean score should be from 2.5 to 3.4 and the low frequency use suggests that the mean score should be lower than 2.5 (Oxford \& Burry-Stock, 1995). Therefore, among the four factors of the international posture, Chinese college students hold high level intercultural friendship orientation in English learning ( $\mathrm{M}=3.81)$; medium level intergroup approach-avoidance tendency $(\mathrm{M}=3.28)$, interest in foreign affairs $(M=3.17)$ and interest in international vocation/activities $(M=2.81)$. IWTC significantly correlate with international posture $(0.26, \mathrm{p}<0.01)$, intercultural friendship orientation in English Learning $(0.34, \mathrm{p}<0.01)$ and intergroup approach-avoidance tendency $(0.19, \mathrm{p}<0.05)$. However, there is no significant relationship between IWTC and the other two factors, which are interest in international vocation/activities

\begin{tabular}{ccc}
\hline Table 1. International posture and correlations with IWTC. & & \\
\hline & Mean (SD) & Correlation with IWTC \\
\hline Intercultural posture & $61.35(6.06)$ & $0.26^{* *}$ \\
\hline intercultural friendship orientation in English Learning (IFO) & $3.81(0.69)$ & $0.34^{* *}$ \\
intergroup approach-avoidance tendency (AAT) & $3.28(0.41)$ & $0.19^{*}$ \\
interest in international vocation/activities (IVA) & $2.81(0.39)$ & 0.02 \\
interest in Foreign Affairs (IFA) & $3.17(1.02)$ & 0.01 \\
\hline
\end{tabular}

Note: $\mathrm{N}=167 ;{ }^{*} \mathrm{p}<0.05$ (two-tailed); ${ }^{* *} \mathrm{p}<0.01$ (two-tailed). 
(0.02) and interest in foreign affairs (0.01). Such results suggest that the higher a students' international posture (or IFO, AAT) is, the more willingness he has to initiate an intercultural communication. However, students' IVA and IFA will not influence their IWTC.

Having established the correlation between the international posture and the IWTC, we use the multiple linear regression to better understand which factor of the international posture can predict the IWTC. We adopt the stepwise method. Earning entry to the model is set at an alpha level of 0.05. But to be removed, a variable must have an associated probability of greater than 0.10 . The result is shown in Table 2.

Table 2 illustrates that only the factor of international friendship orientation (IFO) in English learning has entered into the regression model, all the other three factors failed to enter the regression model for the lack of significant predication to the IWTC. From Table 2, we can find that F $=20.084$, and $p=0.000$, such data indicates that the regression model is effective. $\mathrm{R}^{2}=0.110$, which means that the factor of IFO can explain $11 \%$ variance of the IWTC. Adjusted $\mathrm{R}^{2}=0.105$, which means that IFO can explain $10.5 \%$ variance of IWTC after excluding the influence of the number of the independent variables.

\section{Discussion}

The study investigated the impact of international posture on IWTC. The results showed that Chinese students held a medium to high level of international posture. The international posture and its two factors (IFO \& AAT) hold significant positive relationship with IWTC, which means the higher a Chinese student's international posture is, the more willingness he has to initiate an intercultural communication with the foreigners. Among the four factors of the international posture, only the factor of IFO entered the regression model. The IFO can explain $10.5 \%$ variance of the IWTC, which shows the significant predicative power of IFO. Hence, Chinese college students' IFO can significantly predict their IWTC. On the other hand, it also means that the IWTC can be explained by many other variables since there is nearly $90 \%$ variance which has not been explained. IWTC is a very complex variable and has many influencing factors such as the intercultural communication confidence, communication anxiety, communication apprehension, ethnocentrism and communication competence, etc. Therefore, to investigate the relationship between the IWTC and other influencing factors will be the focus of the future studies.

Our research was built on Yashima's (2002) study of the relationship between the Japanese college students' international posture and their willingness to communicate in English. Yashima's study demonstrated the significant positive relationship between international posture and L2 WTC. Even if the IWTC is somewhat different with the L2 WTC, the Chinese students' intercultural communication is mainly conducted by use of English. Therefore, our study will further extend the result of Yashima’s study. As Yashima (2002) said, it was not surprising that the more internationally orientated an individual was, the more likely he was to be willing to communicate in English. Such tendency has also been proved in the IWTC with the Chinese college students as the subjects.

In addition to the extension of the subjects, our study also further investigated which factor of the international posture could predict students’ IWTC. The multiple linear regression results strongly pointed out the importance of cultivating students' intercultural friendship orientation in English learning. In a context of China where there is not much daily contact with native speakers of English, learners are not likely to have a clear affective reaction to the exact L2 language group; however, attitudes toward English cultures can be created through education and exposure to media. Yashima (2002) indicated that English seemed to represent a certain media in the minds of young Japanese learners. For many learners, English symbolizes the world around China, something that connects them to foreign countries and foreigners with whom they can communicate by using English. Therefore, the factor of intercultural friendship orientation (such as the item of "study English will allow me to know various cultures and people”) in English learning strongly suggests students' affective attitude to the foreigners and the English community. Those students who have high scores in IFO surely hold strong positive

Table 2. Regression analysis between the international posture and IWTC.

\begin{tabular}{ccccccccc} 
& $\mathrm{R}$ & $\mathrm{R}^{2}$ & Adjusted $\mathrm{R}^{2}$ & F change & $\mathrm{B}$ & Beta & $\mathrm{t}$ \\
\hline IFO & 0.332 & 0.110 & 0.105 & 20.084 & 62.998 & 0.332 & 4.482 \\
\hline
\end{tabular}

Note: $\mathrm{F}=20.084 ; \mathrm{p}=0.000$; IFO: International Friendship Orientation in English learning. 
affective attitude towards the foreigners and the English community, therefore, it was not surprisingly to find their high IWTC.

When the individual holds a high level of international posture, it is likely that he has strong interest in the foreign affairs, his purpose of learning English is also oriented by making friends with foreigners which will help him to initiate the intercultural communication. Such results correspond to the study of Gareis et al. (2011) in which the intercultural friendship has a positive relationship with willingness to communication.

\section{Conclusions}

The results of this study accentuate the importance of international posture in the globalizing society through its positive relationship with the IWTC. What is more, IFO (intercultural friendship orientation in English learning) can significantly predict students' IWTC. Such results show that the higher a student's IFO is, the higher IWTC he has.

The limitation of our study is that we only focus on one influencing factor of IWTC. Since international posture only demonstrates one dimension that will influence the IWTC, the further research can continue to explore the other dimensions such as ethnocentrism, intercultural apprehension, intercultural communication confidence, intercultural communication ability, and intercultural communication anxiety, etc. Those further researches can help understand the nature of being fully competent in initiating the intercultural communication better.

Despite of the above-mentioned limitation, our study provides further evidence to confirm that international posture can help students initiate their intercultural willingness to communicate. People influence each other in the process of communication. Intercultural communication is the sharing and construction of meaning through interaction with those from other countries. In the teaching of English, we can help students to strengthen their IWTC by fostering their international posture, especially their intercultural friendship orientation in English learning. With the guide of strong international posture, students will be more willing to engage in the intercultural communication which can expand their communicative repertoires and make the construction of shared meaning easier. IWTC involves readiness to initiate the process of intercultural communication, which will hopefully lead to mutual understanding and trust.

\section{Funding}

This article is funded by the 12th 5-year major project in 2013 of the Educational Science Department of Hubei Province, China (Project Name: study on Chinese college students' willingness to communicate from the ecological perspective; project number: 2013A106).

\section{References}

Errington, J. M. (2009). Motivation, International Posture and China Core Cultural Values: Toward a Theory of Motivation in Chinese ESL. Unpublished Master's Thesis, London: University of London.

Gareis, E., Merkin, R., \& Goldman, J. (2011). Intercultural Friendship: Linking Communication Variables and Friendship Success. Journal of Intercultural Communication Research, 40, 153-171. http://dx.doi.org/10.1080/17475759.2011.581034

Kassing, J. W. (1997). Development of the Intercultural Willingness to Communicate Scale. Communication Research Reports, 14, 399-407. http://dx.doi.org/10.1080/08824099709388683

Lin, Y., \& Rancer, A. S. (2003). Ethnocentrism, Intercultural Communication Apprehension, Intercultural Willingness to Communicate, and Intentions to Participate in an Intercultural Dialogue Program: Testing a Proposed Model. Communication Research Reports, 20, 62-72. http://dx.doi.org/10.1080/08824090309388800

McCroskey, J. C., \& Baer, J. E. (1985). Willingness to Communicate: The Construct and Its Measurement. Paper Presented at the Annual Convention of the Speech Communication Association, Denver.

McCroskey, J. C., \& Richmond, V. P. (1991). Willingness to Communicate: A Cognitive View. In M. BoothButterfield (Ed.), Communication, Cognition, and Anxiety (pp. 19-37), Newbury Park, CA: Sage.

McCroskey, J. C. (1992). Reliability and Validity of the Willingness to Communicate Scale. Communication Quarterly, 40, 16-25. http://dx.doi.org/10.1080/01463379209369817

Pan, M. (2007). Intercultural Communication Apprehension, Ethnocentrism and Their Relationship with Gender: A CrossCultural Comparison between the U.S. and China. Paper Presented at the Annual Meeting of the NCA 93rd Annual Convention, TBA, Chicago. 
Roach, K. D., \& Olaniran, B. A. (2001). Intercultural Willingness to Communicate and Communication Anxiety in International Teaching Assistants. Communication Research Report, 18, 26-35. http://dx.doi.org/10.1080/08824090109384779

Yashima, T. (2002). Willingness to Communicate in a Second Language: The Japanese EFL Context. Modern Language Journal, 86, 55-66. http://dx.doi.org/10.1111/1540-4781.00136

Yashima, T., Zenuk-Nishide, L., \& Shimizu, K. (2004). The Influence of Attitudes and Affect on Willingness to Communicate and Second Language Communication. Language Learning, 54, 119-152. http://dx.doi.org/10.1111/j.1467-9922.2004.00250.x

Yashima, T., \& Zenuk-Nishide, L. (2008). The Impact of Learning Contexts on Proficiency, Attitudes, and L2 Communication: Creating an Imagined International Community. System, 36, 566-585. http://dx.doi.org/10.1016/j.system.2008.03.006 